\section{Proton Irradiation Effects on the Physio-Mechanical Properties and Microstructure of Cold-Worked Molybdenum $\$$}

\section{Simos $\mathbf{N}^{1 *}$, Quaranta $\mathbf{E}^{2}$, Charitonidis $\mathbf{N}^{2}$, Redaelli $\mathbf{S}^{2}$, Bertarelli $\mathbf{A}^{2}$, Mariani $\mathbf{N}^{2}$, Zhong $\mathbf{Z}^{1}$, Ghose $\mathbf{S}^{1}$, Doorhyee $\mathrm{E}^{1}$, Zhong $\mathrm{H}^{3}$ and Kotsina $\mathrm{Z}^{4}$}

\begin{abstract}
High temperature refractory materials and alloys including Mo and TZM have been considered and studied to assess their applicability in fusion reactor applications in addition to spallation targets in particle accelerators. The impacts of neutron, proton and ion irradiation on the properties and microstructure of pure Mo and its combination TZM have been evaluated through illumination damage studies. Cold- worked molybdenum (CW half), described by a microstructure comprising of non-consistently extended grains, has been considered for use in the Large Hadron Collider $7 \mathrm{TeV}$ shaft halo cleaning framework has incited the present investigation. To assess the degradation of key physio-mechanical properties of the cold-worked structure following protracted exposure to proton irradiation as well as the impact of the irradiation temperature on the degradation irradiations with $200 \mathrm{MeV}$ protons at $960^{\circ} \mathrm{C}$ to fluencies $\sim 2 \times 10^{21} \mathrm{p} / \mathrm{cm}^{2}$ and with $28 \mathrm{MeV}$ at below $600^{\circ} \mathrm{C}$ to fluency of $\sim 6 \times 10^{20} \mathrm{p} / \mathrm{cm}^{2}$ were performed at Brookhaven National Laboratory. High energy X-rays at the NSLS and NSLS II synchrotrons were utilized in the post-irradiation evaluation (PIE) to assess the evolution of the microstructure. It was revealed that the cold-worked Mo and in agreement with neutron irradiation studies at high temperatures, suffers serious reduction in tensile strength due to the evolution of defects into dislocation networks. Further, irradiation at temperatures near the full re-crystallization temperature of the cold-worked structure removes the texture of the microstructure induced by cold working.
\end{abstract}

\section{Keywords}

Cold worked molybdenum; Proton irradiation

\section{Introduction}

Molybdenum, alongside other high temperature unmanageable metals and alloys ( $\mathrm{Nb}, \mathrm{Ta}, \mathrm{Cr}, \mathrm{Mo}, \mathrm{W}$ combinations) has been considered for fusion energy applications. Several studies have been conducted over the years addressing the effects of neutrons on molybdenum properties driven by the interest of Mo and its alloys in reactor applications [1-6]. A critical analysis of the operating temperature windows for nine candidate fusion reactor structural materials, including refractory metals such as Mo, TZM, is reported by Zinkle and Ghoniem [1]. The annealing behaviour of irradiation

*Corresponding author: Nikolaos Simos, Brookhaven National Laboratory, Upton, NY 11973, USA, Tel: 344-7590, E-mail: simos@bnl.gov

$\$$ Work performed under the auspices of the US DOE

Received: November 06, 2017 Accepted: November 21, 2017 Published: November 27, 2017 damage in molybdenum was studied in, following neutron irradiation at $60^{\circ} \mathrm{C}$ [2]. It was assessed that no observable damage annealing took place up to $600^{\circ} \mathrm{C}$ but the damage defects showed to increase in size transforming into dislocation loops and dislocation networks at higher temperatures.

Fast neutron irradiation at $460^{\circ} \mathrm{C}$ to fluency of $1.14 \times 10^{26} \mathrm{n} /$ $\mathrm{m}^{2}$ and annealing on the elastic moduli and electrical resistivity of Mo and W were studied using single-crystal samples, resulted to post-irradiation annealing did not restore the pre-irradiation resistivity contrary Young's moduli that were restored to their preirradiation levels [3]. High-temperature heavy ion bombardment of molybdenum, niobium and TZM were conducted in revealing the effect of irradiation temperature on void-induced swelling which is higher for Mo while reaching a maximum at $\sim 900^{\circ} \mathrm{C}$ [4]. Neutron irradiation damage and void lattice formation on the Mo alloy TZM was studied by Abe et al. [5].

Brown and Cost using $800 \mathrm{MeV}$ protons and fluencies up to $10^{20} \mathrm{p} / \mathrm{cm}^{2}$ studied several materials considered for spallation targets that included Mo, Ta, Alloy 718 and 304 stainless steel by focussing on irradiation-induced changes in yield strength, tensile strength and ductility [7]. Results relevant to the present study revealed that tantalum samples retained significant ductility at room temperature, while several molybdenum specimens broke at less than 0.2 percent strain. Wang et al. studied deformation-induced structural transition in body-centred cubic molybdenum and the BCC to the metastable FCC transitions at room temperature under excessive strain in the proximity of crack tips using transmission elector microscopy [8]. The effects of $200 \mathrm{MeV}$ proton irradiation on the molybdenum carbidegraphite compound are reported in the interaction of molybdenum with graphite at high temperature $[9,10]$. Proton irradiation of other refractory metals and beam intercepting materials were studied and reported in [11-13].

In this study, proton radiation effects on the physio-mechanical property changes and the microstructural evolution of the $50 \%$ cold-worked Mo, it has been studied prompted by the interest in the material to be used in the High Luminosity LHC phase $7 \mathrm{TeV}$ beam intercepting devices (i.e., collimation systems). Specifically, the collimation system of the LHC consists of $>100$ units placed at specific locations around the LHC ring and is a complex combination of machine protection and beam halo cleaning system and needs to be capable of handling the enormous amount of energy stored in LHC beams. Resistance to thermal shock from a miss-steered $7 \mathrm{TeV}$ beam, extreme dimensional and thermal stability and high resistance to physical property degradation from long-term irradiation are some of the key parameters that are sought in the materials of choice.

The thermal stability of this cold-worked refractory metal was assessed prior to irradiation using Differential Scanning Calorimetry (DSC) and Thermo-Gravimetric Analysis (TGA) to understand its oxidation kinetics. In addition, dimensional stability using a high sensitivity dilatometer was evaluated as well as its mechanical behaviour and the impact of high-temperature annealing. Two irradiation campaigns were conducted to evaluate irradiationinduced changes, one using $200 \mathrm{MeV}$ protons from the BNL Linac at the BLIP beam line/target station with $\mathrm{T}_{\text {irr }}$ estimated to be $\sim 960^{\circ} \mathrm{C}$ to 
Citation: Simos N, Quaranta E, Charitonidis N, Redaelli S, Bertarelli A, et al. (2017) Proton Irradiation Effects on the Physio-Mechanical Properties and Microstructure of Cold-Worked Molybdenum\$. J Nucl Ene Sci Power Generat Technol 6:4.

a peak fluency of $2 \times 10^{21} \mathrm{p} / \mathrm{cm}^{2}$ and the second using a focussed 28 $\mathrm{MeV}$ proton beam of the BNL Tandem van de Graaff accelerator at low temperature (irradiation chamber temperature $\sim 240 \mathrm{~K}$ ) and to a fluency of $6.3 \times 10^{20} \mathrm{p} / \mathrm{cm}^{2}$ Following irradiation, irradiation analysis macroscopic post-irradiation evaluation (PIE) was conducted at the BNL Isotope Extraction Facility, followed by microscopic PIE using high energy X-ray diffraction analysis at the NSLS X17B1 and X17A beam lines and the XPD beam line of the NSLS II synchrotrons. Results of both the macroscopic and the X-ray diffraction PIE are presented in the following sections of the manuscript.

\section{Experimental}

The Mo explored for use in LHC collimation system and studied here is a commercially pure, cold worked structure produced by Plansee Group, Austria [14]. The material is formed by sintering of pure Mo powder at high temperature (over $2000^{\circ} \mathrm{C}$ ) followed by cold working up to $50 \%$ reduction in thickness. The resulting microstructure consists of elongated Mo grains (Figure 1) with few small inclusions (mostly $\mathrm{Mo}_{2} \mathrm{C}$ ) that are finely dispersed within the Mo matrix. We therefore refer to the Mo of the present study hereafter as 50\% CW Mo.

It has been observed [Plansee] that ductility and fracture toughness of Mo decrease as the recrystallization level increases. This implies that the recrystallization temperature is a decisive factor in using the material under a desired set of parameters, such as irradiation temperature. It is anticipated that the micro-structure of the material changes at temperatures exceeding the recrystallization temperature. The induced restructuring of the Molybdenum grain reduces the strength and its hardness leading to premature fracture. The instituted cold working is expected to enhance/increase the elongation of the treated material to fracture, especially in the cold working direction. Manufacturer claims that the applied cold work maintains adequate physio-mechanical properties in the transverse direction of the resulting structure. For the $50 \%$ CW Mo under study, $100 \%$ recrystallization was achieved following annealing for 1 hour at $1100^{\circ} \mathrm{C}$ [14]. For comparison, the corresponding re-crystallization temperature for the Mo alloy $\mathrm{TMZ}$ was $\sim 1400^{\circ} \mathrm{C}$.

The received cold-worked Mo was characterized in its preirradiation state exhibiting density $\rho=10.22 \mathrm{~g} / \mathrm{cm}^{3}, \mathrm{~T}_{\text {melt }} \sim 2623^{\circ} \mathrm{C}$, thermal conductivity $\mathrm{W}=138 \mathrm{~W} / \mathrm{m}-\mathrm{K}$, average $\mathrm{CTE}=5\left[10^{-6} \mathrm{~K}^{-1}\right]$, Young's modulus E=330 GPA and tensile strength $>660 \mathrm{MPa}$ [15]. Special test samples of this Mo material have been designed and produced for the irradiation studies aiming to address physio- mechanical property changes during post-irradiation (PIE) analysis. Figure 2 depicts the schematics of the two types used throughout, one used for the dimensional stability changes (Figure $2 \mathrm{~b}$ ) termed CTE type hereafter and the second, termed tensile, for macroscopic stress-strain behaviour and X-ray diffraction (Figure 2a). A special arrangement of these two types was adopted into a vacuum capsule prior to inserting the capsule into the $200 \mathrm{MeV}$ proton beam. During the $28 \mathrm{MeV}$ experiment only tensile test samples were utilized.

\section{Pre-irradiation characterization of Mo-thermal stability}

The thermal stability of the $50 \% \mathrm{CW}$ Mo was studied using the experimental facilities at the BNL Center of Functional nanomaterial's (CFN). The objective was to (a) address similarities of this refractory metal with the behaviour of other refractory metals studied recently (tungsten and tantalum) and which exhibited very distinct "anomalies" in the temperature range between $300-400^{\circ} \mathrm{C}$ attributed to magnetostriction, and (b) establish oxidation behaviour and kinetics of the CW Mo. Figure 3 depicts the thermal stability of the $50 \% \mathrm{CW}$ Mo up to $600^{\circ} \mathrm{C}$. Also depicted is a faint, but distinct deviation from the expected heat flux line indicating that a "transition" is taking place. The oxidation behaviour of the CW Mo is shown in Figure 4. As seen, significant oxidation taking place throughout the material structure is triggered around $800^{\circ} \mathrm{C}$.

\section{Irradiation experiments o Mo}

As mentioned in the introduction section, two irradiation campaigns were conducted, one at high irradiation temperature $\left(\sim 960^{\circ} \mathrm{C}\right)$ using $200 \mathrm{MeV}$ protons, and the second at much lower temperature $\left(\sim 420^{\circ} \mathrm{C}\right.$ within the irradiated zone of the Mo sample of Figure 2a) while the ambient operating temperature within the vacuum chamber was $\sim 240 \mathrm{~K}$. Specifics of the two irradiation configurations are provided below.

Phase I - High temperature/high fluency: A specially configured array of tensile-type and CTE-type Mo specimens was encapsulated within a vacuum capsule which was lowered into the $200 \mathrm{MeV}$ proton beam of $110 \mu \mathrm{A}$ current at the BLIP beam line/target station. The operating temperature was estimated to be $\sim 960^{\circ} \mathrm{C}$ using a well benchmarked thermo-mechanical model based on the FLUKA $[16,17]$ interfaced with the LS-DYNA software [18]. The $960^{\circ} \mathrm{C} \mathrm{T}_{\text {irr }}$ was assessed to be the temperature within the 1-sigma of the beam, dropping to slightly lower values at the larger beam $\sigma$. The peak fluency accumulated (based on measured beam current and beam
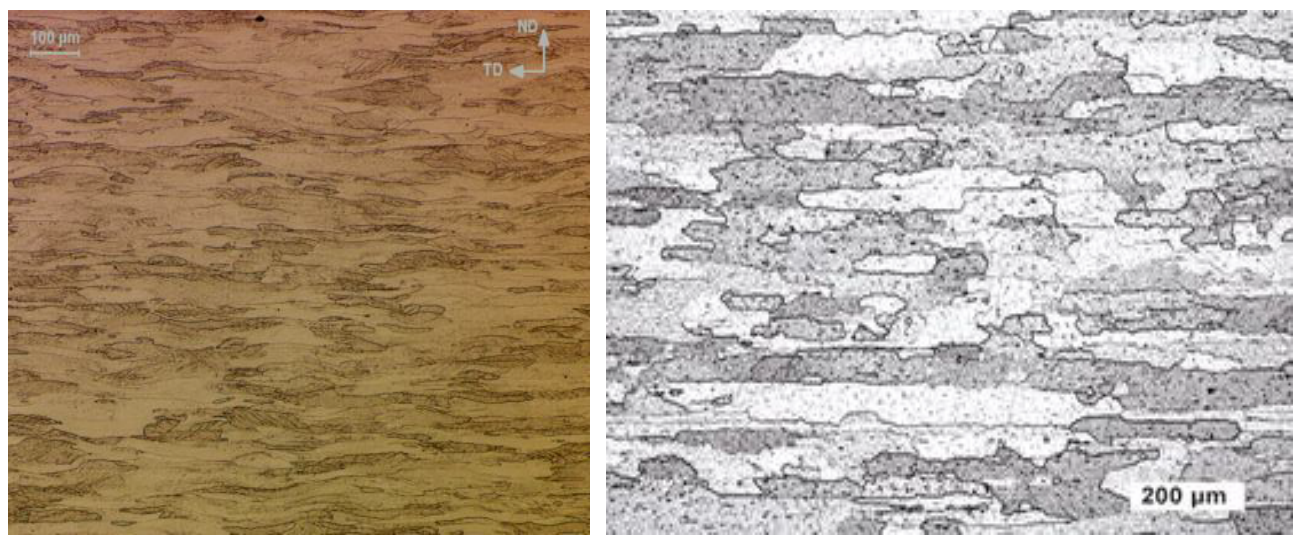

Figure 1: Optical microscopy of molybdenum microstructure: The grains are elongated and there are no visible pores and inclusions $[15,16]$ 

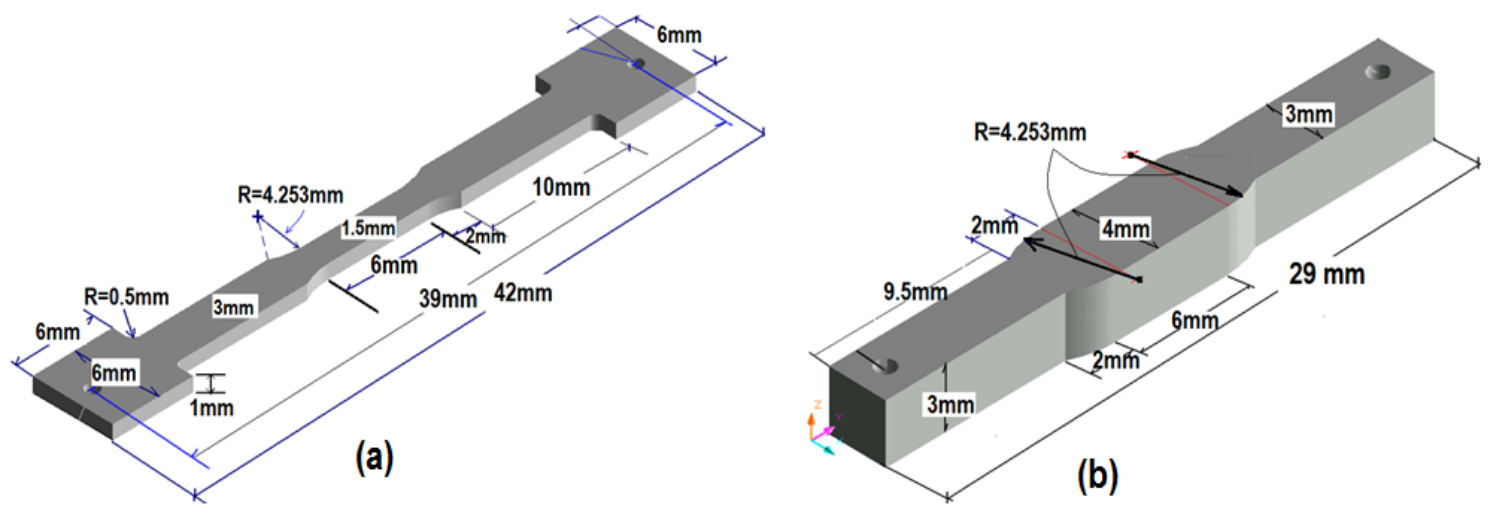

Figure 2: Geometries of irradiated Mo specimens. (a) Tensile sample and (b) CTE-type sample.
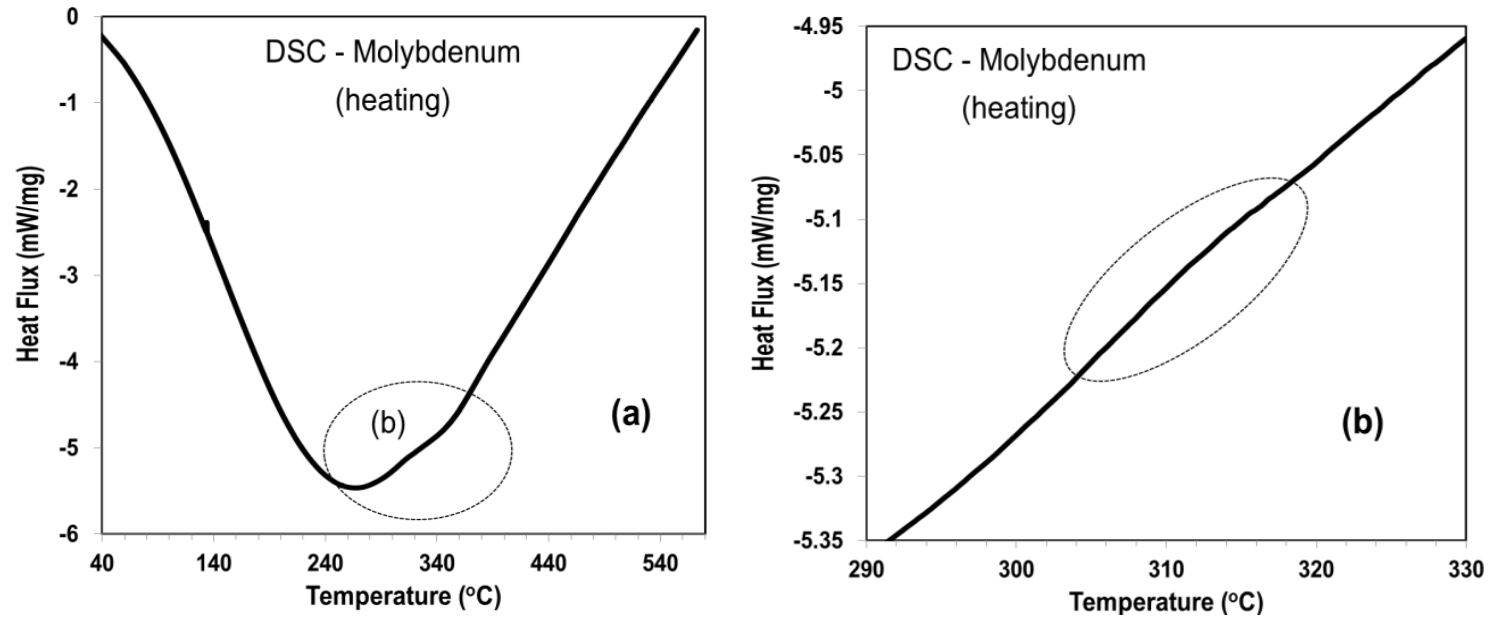

Figure 3: DSC analysis of the $50 \% \mathrm{CW}$ Mo. Shown in (b) is the presence of a "transition" near $320^{\circ} \mathrm{C}$

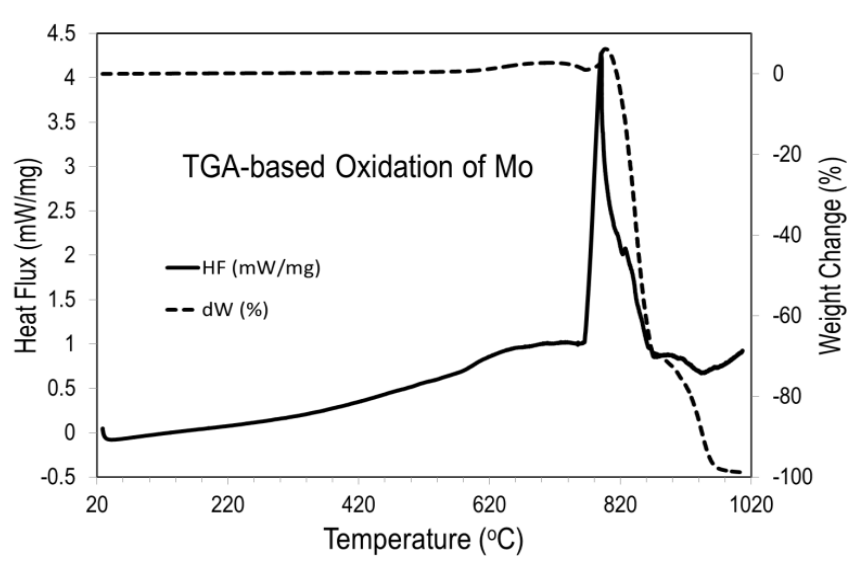

Figure 4: TGA-based oxidation behavior of the $50 \% \mathrm{CW}$ Mo.

profile) was $2 \times 10^{21} \mathrm{p} / \mathrm{cm}^{2}$. Both CTE-type and tensile specimens from this irradiation were used for both macroscopic and $\mathrm{x}$-ray diffractionbased microscopic PIE.

Phase II- Low temperature/high fluency: Using the $28 \mathrm{MeV}$ protons of the BNL Tandem quickening agent, tractable sort examples of the half $\mathrm{CW}$ Mo (Figure 2a) were lighted with a tight profile bar $(1 \mathrm{~mm} \times 1 \mathrm{~mm}]$. The beam current was $2 \mu \mathrm{A}$ resulting in a fluency of $\sim 6.3 \times 10^{20} \mathrm{p} / \mathrm{cm}^{2}$. While the fluency of this irradiation phase was $\sim$ half what was achieved with the $200 \mathrm{MeV}$ protons at BLIP, the damage induced over the irradiated spot within the gauge of the tensile specimen is expected to be larger due to the elimination of damage annealing during irradiation, a process that is more effective in reversing damage than post-irradiation annealing. Because of the very concentrated damage area, the irradiated CW Mo specimens were only studied using diffraction of high-energy X-rays over the affected zone.

\section{Radiation damage assessment}

Both macroscopic and microscopic PIE was directed on the illuminated 50\% CW Mo and compared with as-received and annealed specimens. Of primary interest during the current phase of the research are changes in the dimensional security, effects on strength and stress-strain behavior and finally irradiation-induced evolution in the microstructure. These are addressed within the following subsections.

Proton irradiation effects on dimensional stability: Using a high-sensitivity LINSEIS dilatometer at the Isotope Processing facility of BNL, the dimensional stability and thermal expansion coefficient 
Citation: Simos N, Quaranta E, Charitonidis N, Redaelli S, Bertarelli A, et al. (2017) Proton Irradiation Effects on the Physio-Mechanical Properties and Microstructure of Cold-Worked Molybdenum\$. J Nucl Ene Sci Power Generat Technol 6:4.

(CTE), as a function of temperature and dose, we assessed. Shown in Figure 5 are traces of the first post-irradiation thermal cycle up to $710^{\circ} \mathrm{C}$. Important to note is the presence of an inflection point in the unirradiated $\mathrm{CW}$ Mo around $520^{\circ} \mathrm{C}$ which shifts upward with irradiation dose, disappearing at the peak dose of $2 \times 10^{21} \mathrm{p} / \mathrm{cm}^{2}$ which is accompanied with high irradiation temperatures $\left(\mathrm{T}_{\text {irr }} \sim 960^{\circ}\right)$ as it is clearly depicted in Figure 5b. Figure 6a depicts the dimensional changes as a function of temperature and dose associated with the second post-irradiation thermal cycle to $710^{\circ} \mathrm{C}$ while Figure $6 \mathrm{~b}$ shows the evolution of CTE as a function of temperature and dose. A general increase of the CTE, as a function of fluency is noted from Figure 6a, while the CTE of the unirradiated CW Mo is in agreement with the average CTE obtained $[14,19]$. As seen in Figure $6 \mathrm{~b}$ the higher the irradiation temperature the less the CTE is affected or increased as compared to the unirradiated material, regardless of the dose, due to the annealing of damage taking place simultaneously.

The presence of the faint transition appearing during the Differential Scanning Calorimetry (DSC) analysis is further evaluated and attempt was made to correspond it with comparative magnetostrictive changes watched for other headstrong metals, for example, Ta and W. Figure $7 \mathrm{a}$ is a comparison of the dimensional changes in CW Mo and Ta over the same temperature range and for the same proton fluency. The one parameter difference is the higher irradiation temperature of CW Mo as compared to Ta. As observed in Figure 7a, Ta exhibits such transitions that are detectable even by dilatometer both during the heating and the cooling phases of the thermal cycle. For Mo, such transition is only detectable for the unirradiated state during the cooling cycle (shown with arrows). The presence of the transitions, attributed to magnetostriction in Ta and also in $\mathrm{W}$ that is not shown here is depicted in Figure $7 \mathrm{~b}$ for two different proton fluencies along with the unirradiated state [14].

\section{Effects of proton irradiation on strength and stress-strain}

The effect of proton irradiation under high irradiation temperature $\left(\mathrm{T}_{\text {irr }} \sim 960^{\circ} \mathrm{C}\right)$ on the mechanical strength of the 50 CW Mo was studied under the following $200 \mathrm{MeV}$ irradiation and compared to the unirradiated state. Figure 8 depicts the stress-strain relation of the CW Mo. As noted, the unirradiated material is brittle with a tensile strength of $\sim 800 \mathrm{MPa}$, a value that corresponds to the manufacturer's specs for the stress-relieved Mo [15]. As noted previously, it is expected that above the recrystallization temperature (or within the temperature range where re-crystallization is taking place) the strength of the material will reduce along with its hardness. To assess the effect, samples previously annealed to $1000^{\circ} \mathrm{C}$ were tension-tested and compared with the untreated counterparts. Indeed, as shown in Figure 8 (red dotted trace) the strength of the material reduces considerably.

Irradiations at elevated temperatures have also a dramatic effect. As it seen in Figure 8 irradiation to $5 \times 10^{20} \mathrm{p} / \mathrm{cm}^{2}$ (accompanied
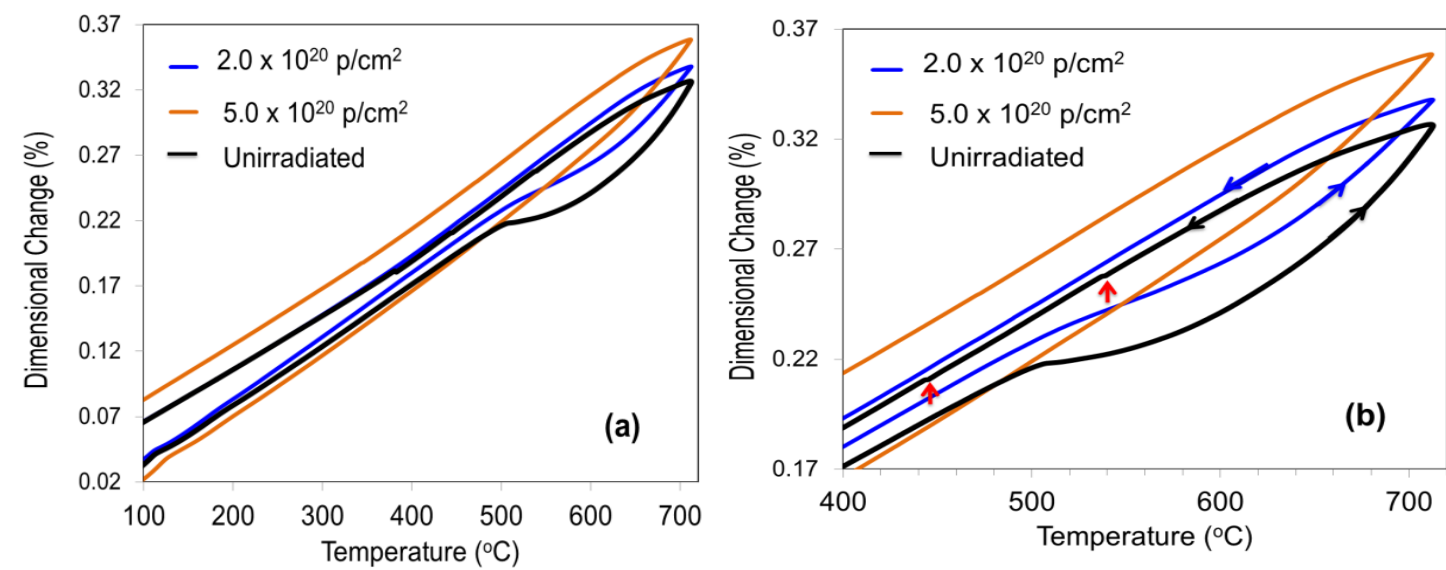

Figure 5: Dimensional stability of the 50\% CW Mo during the first post-irradiation thermal cycle.
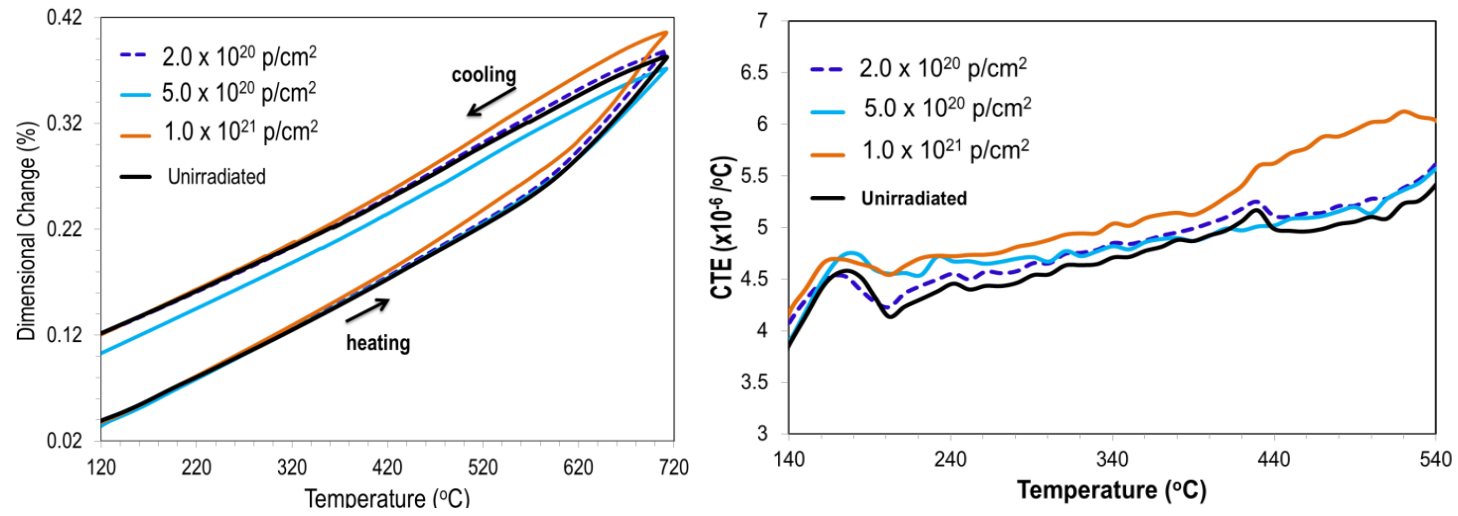

Figure 6: (a) Post-irradiation annealing ( $2^{\text {nd }}$ thermal cycle) of irradiated Mo and, (b) thermal expansion coefficient as a function of temperature and dose. 
Citation: Simos N, Quaranta E, Charitonidis N, Redaelli S, Bertarelli A, et al. (2017) Proton Irradiation Effects on the Physio-Mechanical Properties and Microstructure of Cold-Worked Molybdenum\$. J Nucl Ene Sci Power Generat Technol 6:4.
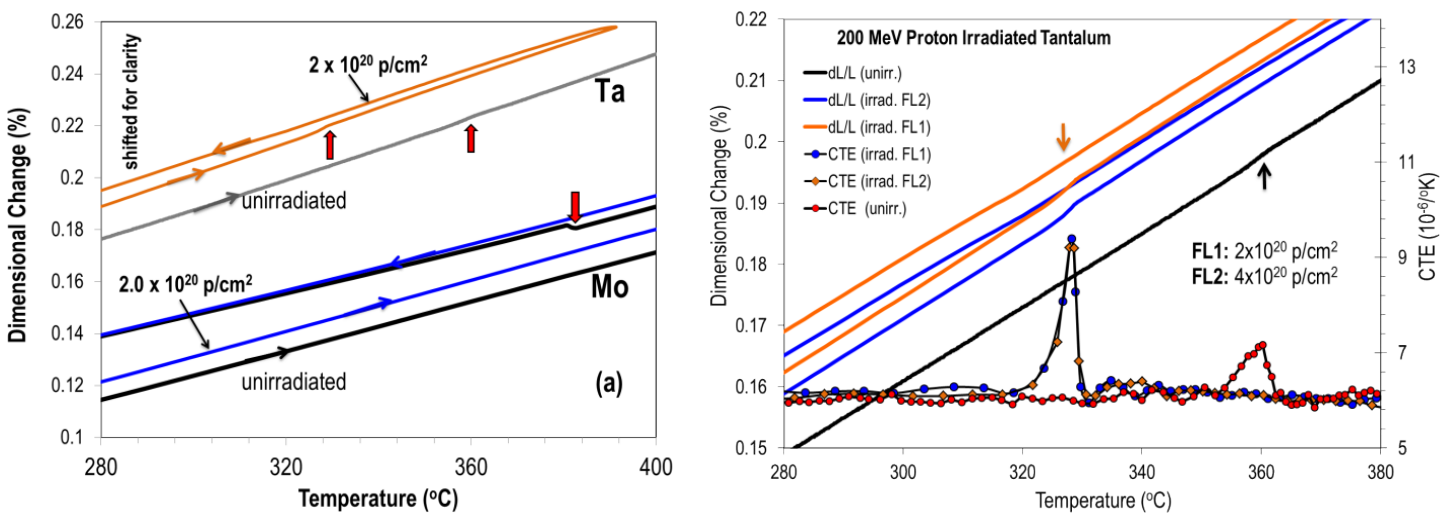

Figure 7: (a) Dimensional change comparison with irradiated Ta to same fluency, and (b) Ta magnetostriction "anomaly" in dimensional change and CTE in the temperature window $320-360^{\circ} \mathrm{C}$.

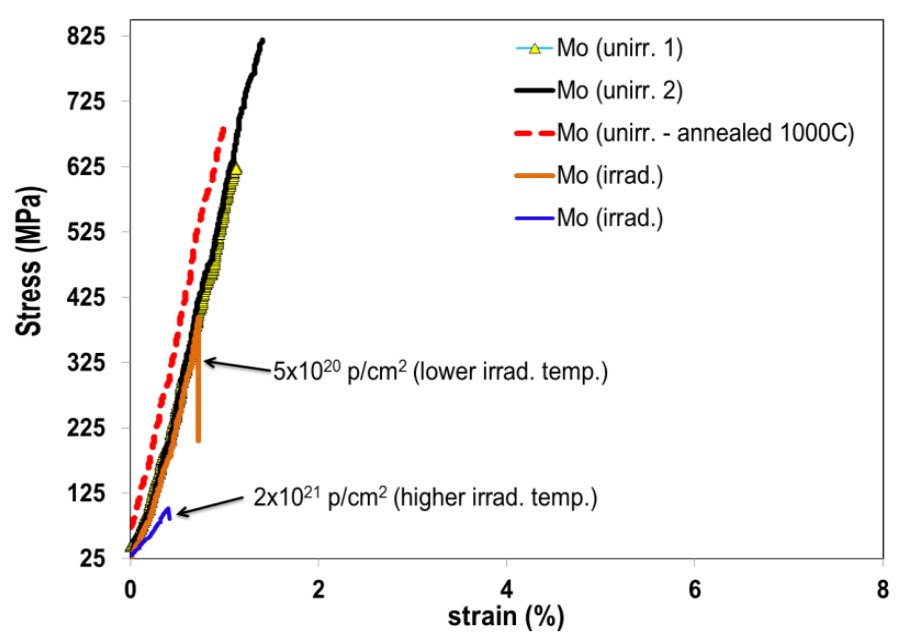

Figure 8: Stress-strain behavior of $50 \% \mathrm{CW}$ Mo as a function of proton fluency and annealing

with $\mathrm{T}_{\text {irr }}<960^{\circ} \mathrm{C}$, but still above $800^{\circ} \mathrm{C}$ ) leads to an abrupt rupture at approximately half the as-received material strength. As also noted in, if Mo is heated above a certain temperature, it loses its brittleness and becomes ductile fracturing at low stress [14]. This is actually observed as a result of the peak fluency (associated with the peak irradiation temperature) where the material fails at extremely low stress. The stress-conduct appeared in Figure 8 following light at raised temperatures can be clarified in view of neutron illumination and strengthening at lifted temperatures where above $600^{\circ} \mathrm{C}$ the irradiation-induced defects evolve into dislocations and eventually, as the temperature increases, into well-developed dislocation networks, resulting in the dramatic reduction of the tensile strength. Similar behavior was also observed by Brown and Cost where the mechanical properties of $800 \mathrm{MeV}$ proton-irradiated metals, including Mo, were studied [7]. For the sake of comparison, the stress-strain behavior of irradiated CW Mo is compared with that of Ta and shown in Figure 9.

Microstructural characterization of irradiated Mo using high energy X-rays

Irradiation-induced changes in the microstructure of the $50 \%$ CW Mo were studied by utilizing high energy X-rays at the BNL two synchrotrons, the now decommissioned NSLS and the NSLS II which is currently the world's brightest light source. At NSLS the X17B1 beam line with the $200 \mathrm{keV}$ polychromatic X-rays was utilized in conjunction with the Energy Dispersive X-ray Diffraction (EDXRD) technique. The X17B1 beam line also enabled the use of a special experimental stage that facilitated in situ four-point-bending (FPB) stress in the sample being interrogated. Monochromatic, $70 \mathrm{KeV}$ $\mathrm{X}$-rays at the X17A beam line of NSLS was also used to assess the microstructural changes of the $28-\mathrm{MeV}$ irradiated CW Mo samples using transmission mode and PDF technique. The highly activated CW Mo samples that were exposed to the $200 \mathrm{MeV}$ protons at BLIP were evaluated using the $67 \mathrm{keV}$ X-rays at the XPD beam line of the NSLS II in conjunction with the experimental stage facilitating in-situ stress (FPB).

Given the cold-working treatment of the Mo structure of interest and the potential implications into its microstructure the as-got CW Mo was assessed widely in each of the three beam lines that were utilized as a part of the investigation. The first four crystallographic reflections $(110,200,211$ and 220) of the as-received and of the annealed to $1000^{\circ} \mathrm{C} \mathrm{bcc} \mathrm{Mo} \mathrm{are} \mathrm{shown} \mathrm{and} \mathrm{compared} \mathrm{in} \mathrm{Figure} \mathrm{10.} \mathrm{As}$ seen in Figures 10a and 10b, the as-received structure shows a pile-up (jagged trace) resulting from the texture exhibited by the material as a result of the excessive cold-working and grain elongation (Figure 1). Figures $10 \mathrm{c}$ and $10 \mathrm{~d}$ do not show such behavior indicating that the corresponding crystallographic planes did not distort during 
Citation: Simos N, Quaranta E, Charitonidis N, Redaelli S, Bertarelli A, et al. (2017) Proton Irradiation Effects on the Physio-Mechanical Properties and Microstructure of Cold-Worked Molybdenum\$. J Nucl Ene Sci Power Generat Technol 6:4.

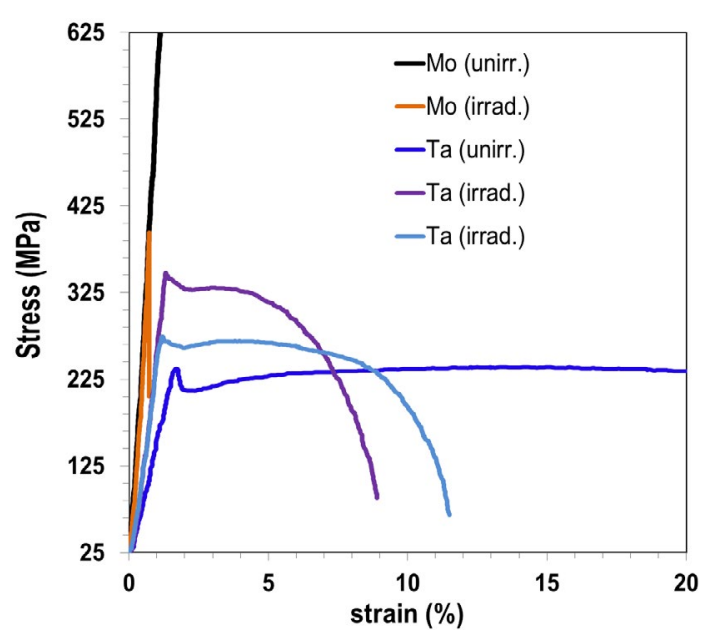

Figure 9: Comparison of the irradiated $50 \% \mathrm{CW}$ Mo with irradiated Ta.
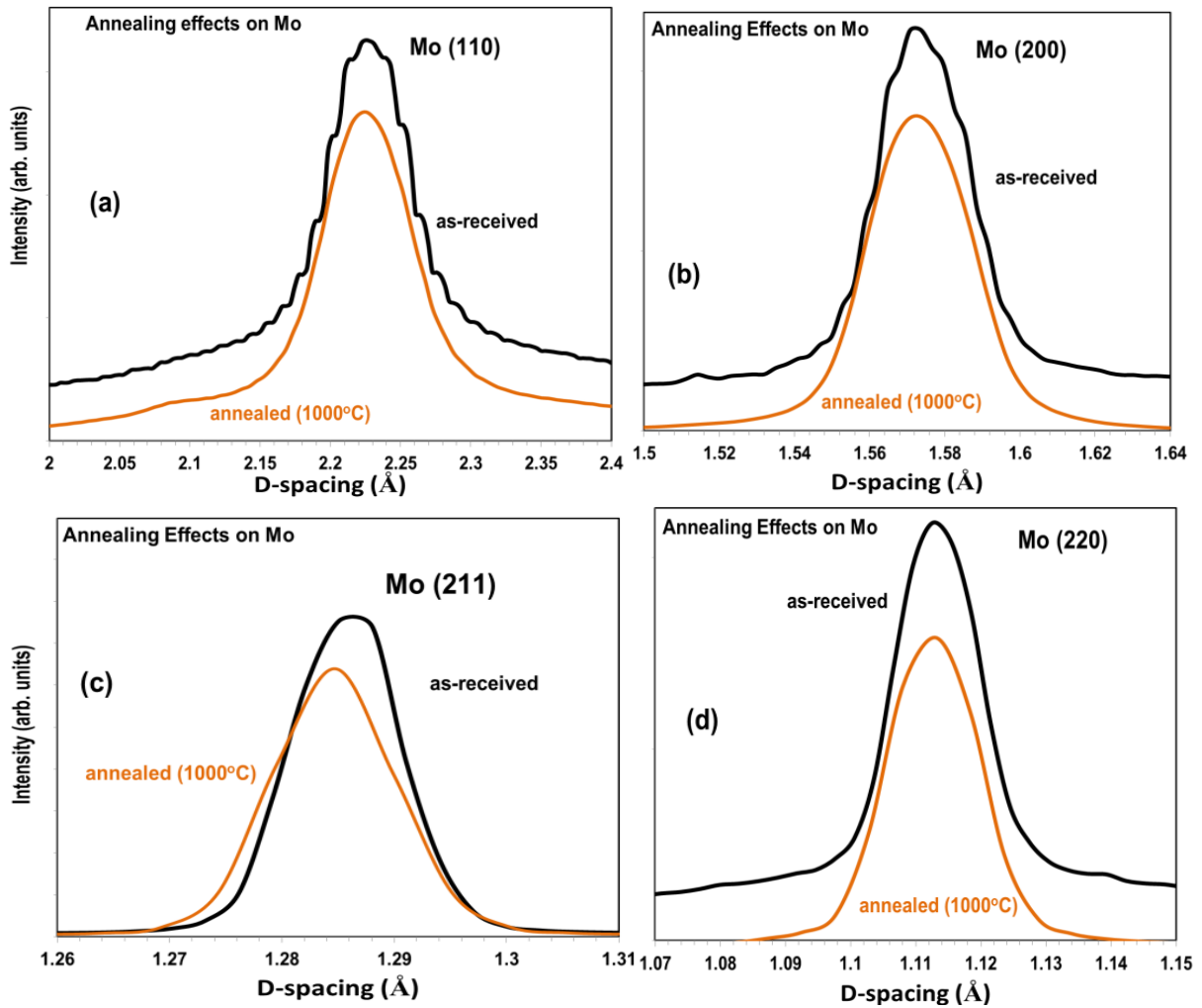

Figure 10: Crystal plane reflection comparison between as-received (cold-worked) Mo and annealed to $1000^{\circ} \mathrm{C}$, at which point the Mo recrystallizes to a large degree.

cold working (i.e., first two planes, 110 and 200, are easier to deform than the 211 and 220). The non-uniformity in the elongation of the grains induced by the cold-working is assessed by the authors to be the reason for the observed behavior. Annealing at close to the complete re-crystallization temperature of $1100^{\circ} \mathrm{C}$ has re-crystallized the microstructure leading to smooth (as expected) crystallographic reflections.

The azimuthal variation of the various reflections, indicating texture, was further detailed according to the schematic of (Figure 11c) where the $\varphi$ range $0-90^{\circ}$ was divided into a number $\Delta \varphi$ slices using the Fit2D software with $\Delta \varphi=4^{\circ}$.

Figure 12 shows the azimuthal variation of the crystallographic reflections (including variation in the corresponding d-spacing) for the (110), (200), (211) and (220). These clearly demonstrate the textured microstructure of the as-received Mo (shown in the Figure 1 micrographs).

Irradiations at Tandem with $28 \mathrm{MeV}$ protons and with light temperatures well underneath the full re-crystallization temperature 
Citation: Simos N, Quaranta E, Charitonidis N, Redaelli S, Bertarelli A, et al. (2017) Proton Irradiation Effects on the Physio-Mechanical Properties and Microstructure of Cold-Worked Molybdenum\$. J Nucl Ene Sci Power Generat Technol 6:4.
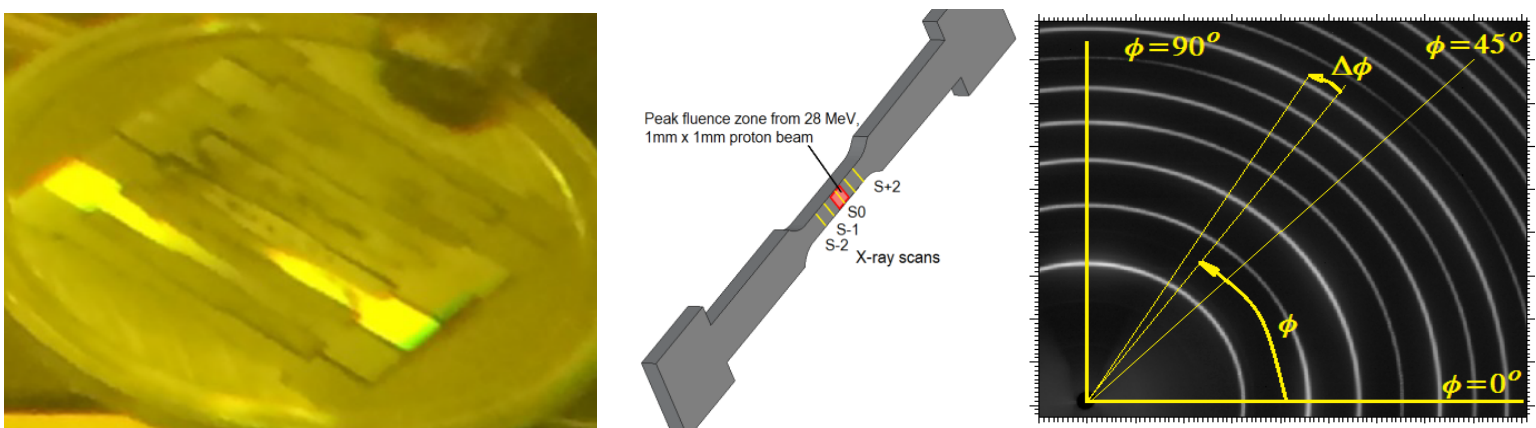

Figure 11: (a) CW Mo sample array inside BNL the hot cell following irradiation with $200 \mathrm{MeV}$ protons at $960^{\circ} \mathrm{C}$, (b) schematic of scanning location of Mo samples irradiated with $28 \mathrm{MeV}$ protons at BNL Tandem, and (c) Azimuthal analysis of the 2-D detector diffraction image using the FIT2D [18] software.
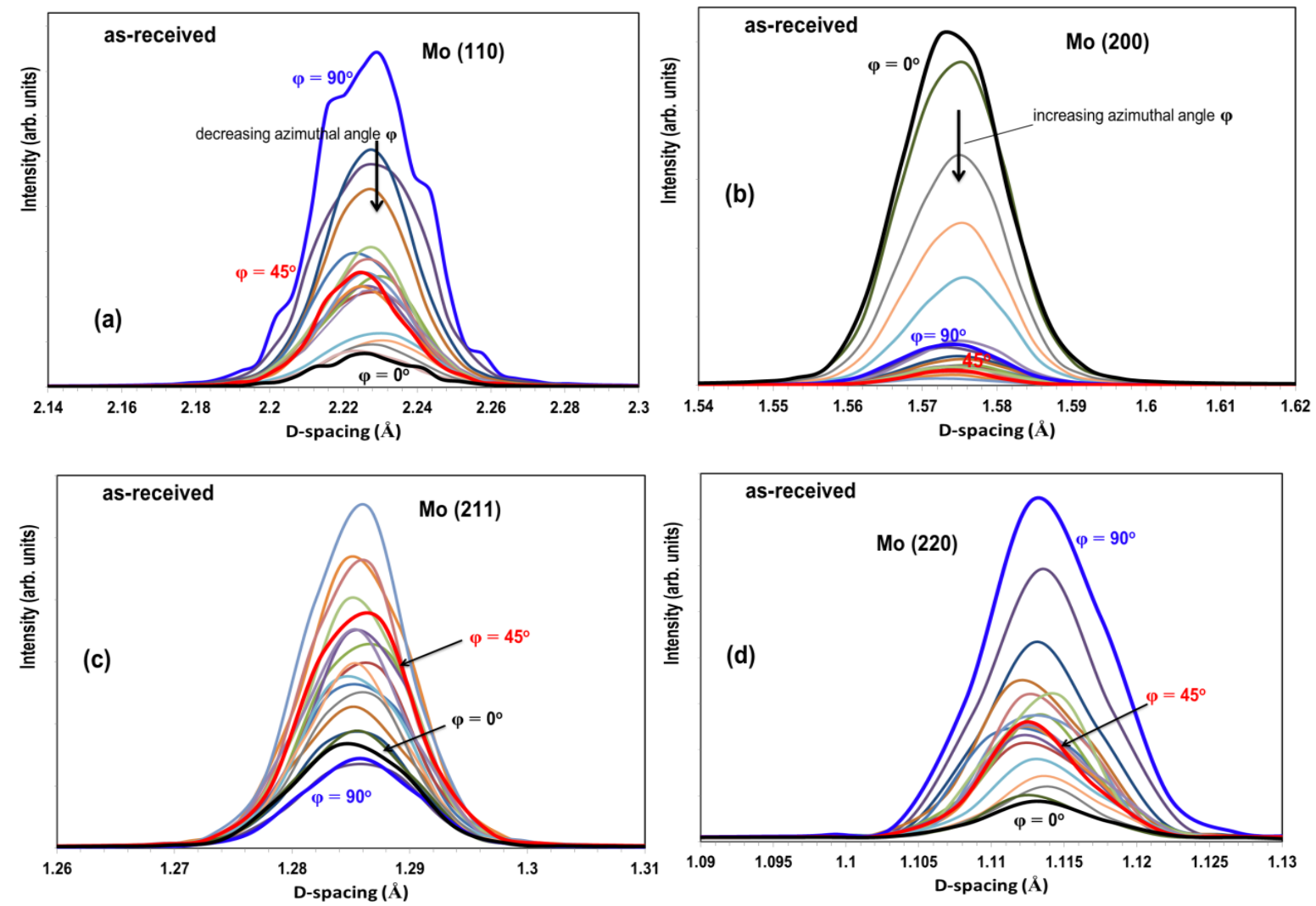

Figure 12: Crystal plane reflections in as-received Mo.

of $1100^{\circ} \mathrm{C}$ and their impact on the microstructure are appeared in (Figure 13) for differing fluency levels. The variation in fluency is achieved by conducting $\mathrm{X}$-ray scanning of the irradiated Mo specimen according to the schematic of Figure 11b. Indicated in Figures $11 \mathrm{~b}$ and 13a-13d) are the scan locations across the tensile-type specimen gauge and across the $28 \mathrm{MeV}$ proton beam spot exposed to a peak fluency of $6.3 \times 10^{22} \mathrm{p} / \mathrm{cm}^{2}$. Because no high temperature annealing was taking place simultaneously with irradiation, the crystallographic reflections (110) and (200) maintain the same textured character that was previously observed (Figure 10). Similarly, the stiffer planes (211) and (220) during the low temperature irradiation maintain their smooth character exhibited prior to irradiation.
The microstructural characteristics of the $\mathrm{CW}$ Mo irradiated at high temperature and higher fluency $\left(\mathrm{T}_{\text {irr }} \sim 960^{\circ} \mathrm{C} ; 2 \times 10^{21} \mathrm{p} / \mathrm{cm}^{2}\right)$ show distinct differences from their low temperature counterparts. Figure 14 depicts the $2 \mathrm{D}$ detector image for the unirradiated (annealed) and the irradiated CW Mo. Driven by the annealing taking place simultaneously with irradiation as a result of the high irradiation temperature, the diffraction images of unirradiated and irradiated Mo exhibit only subtle differences. Detailed comparison of the unirradiated (annealed) and the irradiated states over selected crystallographic reflections are depicted in Figures 15a-15c, which show the (110) and (200) reflections respectively, the texture, seen as pile-up of reflections due to cold-working in Figure 10, has almost disappeared indicating that the material has re-crystallized This is 
Citation: Simos N, Quaranta E, Charitonidis N, Redaelli S, Bertarelli A, et al. (2017) Proton Irradiation Effects on the Physio-Mechanical Properties and Microstructure of Cold-Worked Molybdenum\$. J Nucl Ene Sci Power Generat Technol 6:4.
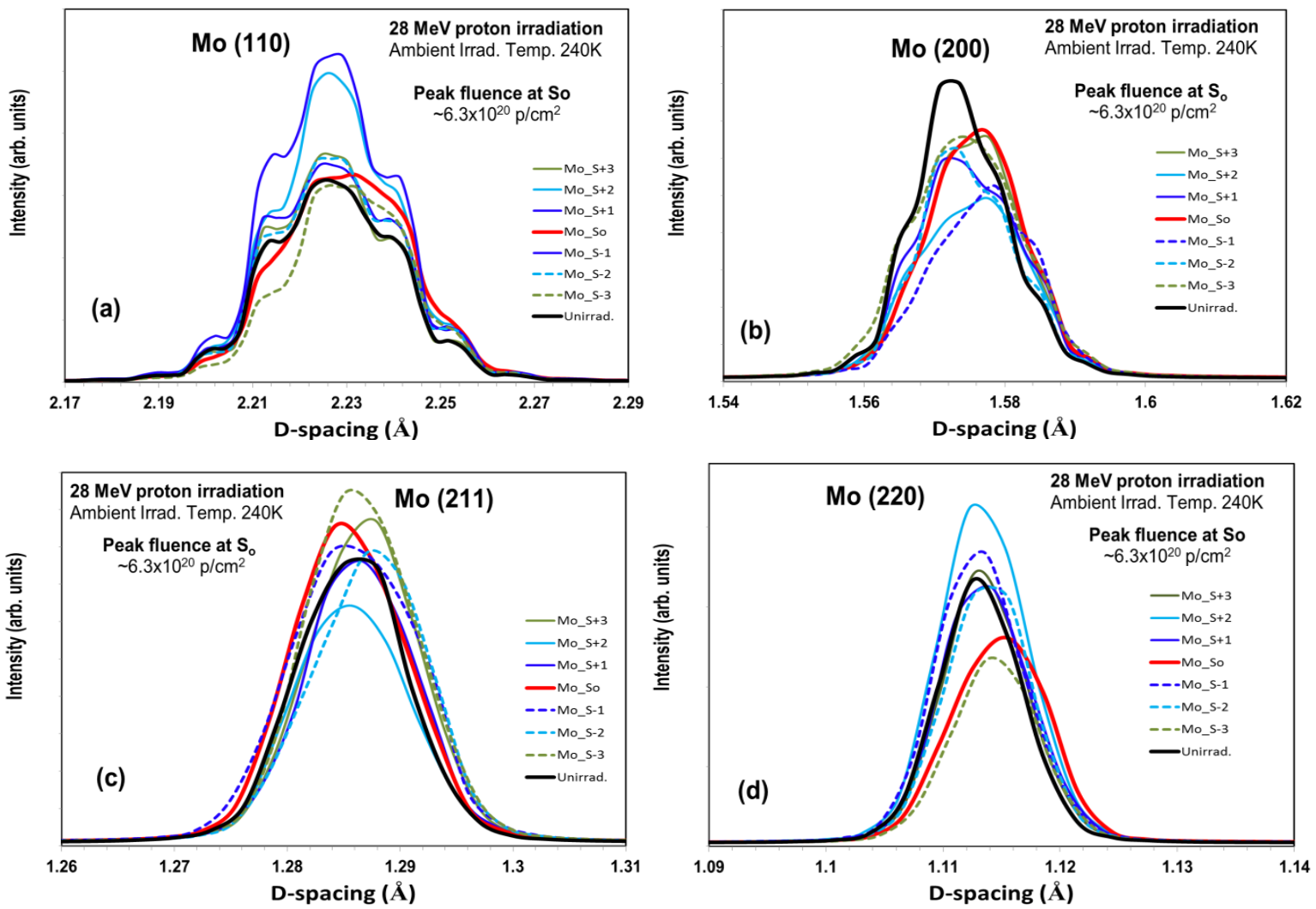

Figure 13: Crystal plane reflection comparison between as-received and proton-irradiated Mo.
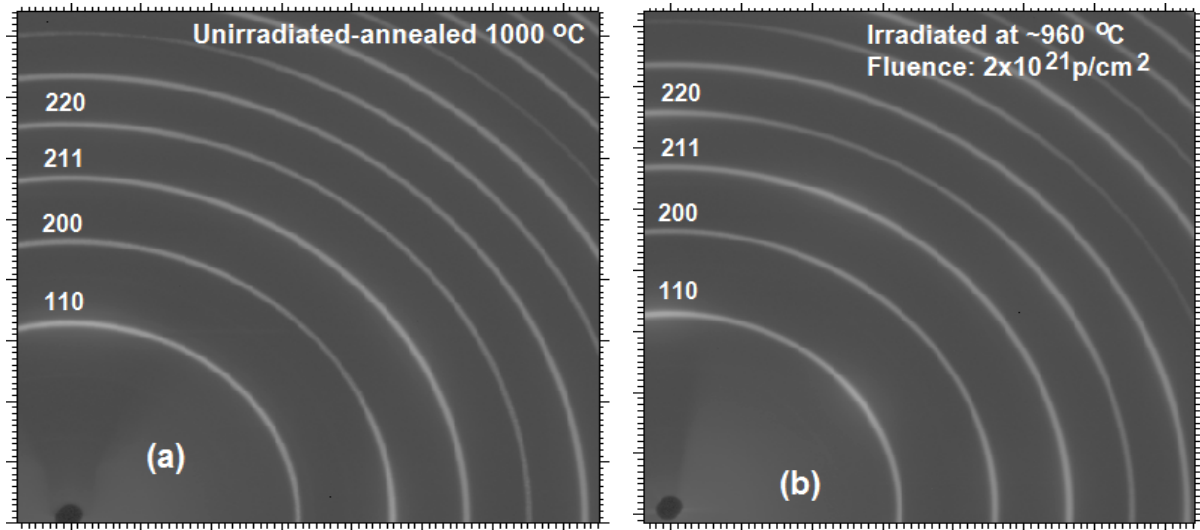

Figure 14: Diffraction pattern comparison between as-received and proton-irradiation Mo.

attributed to the fact that irradiation with $200 \mathrm{MeV}$ protons took place at a temperature approaching the full re-crystallization temperature $1100^{\circ} \mathrm{C}$ of the material. Also shown in Figures $15 \mathrm{a}-15 \mathrm{c}$ ) are the proton irradiation effects on the microstructure of the Mo material for each of the selected crystallographic reflections manifested in terms of d-spacing shifts and broadening.

In a study by Wang et al. [8], deformation-induced structural transitions in body-centered cubic molybdenum have been studied and reported prompted by the thesis that, while transformation coupled with plasticity has been observed in numerous alloys and ceramics, plastic deformation via structural transitions in pure molybdenum were never reported. In the study by Wang et al. [8], it was demonstrated a structural transformation of the BCC structure to a metastable FCC lattice in the vicinity of crack tips in Mo under straining using transmission electron microscopy. In the present study, by utilizing the special experimental stage facilitating in situ four-point-bending (FPB) stress during X-ray interrogation, possible BC-to-FCC transformations in the already cold-worked BCC Mo structure were explored by subjecting the material to high state of stress in a process depicted in Figure 16a. 
Citation: Simos N, Quaranta E, Charitonidis N, Redaelli S, Bertarelli A, et al. (2017) Proton Irradiation Effects on the Physio-Mechanical Properties and Microstructure of Cold-Worked Molybdenum\$. J Nucl Ene Sci Power Generat Technol 6:4.
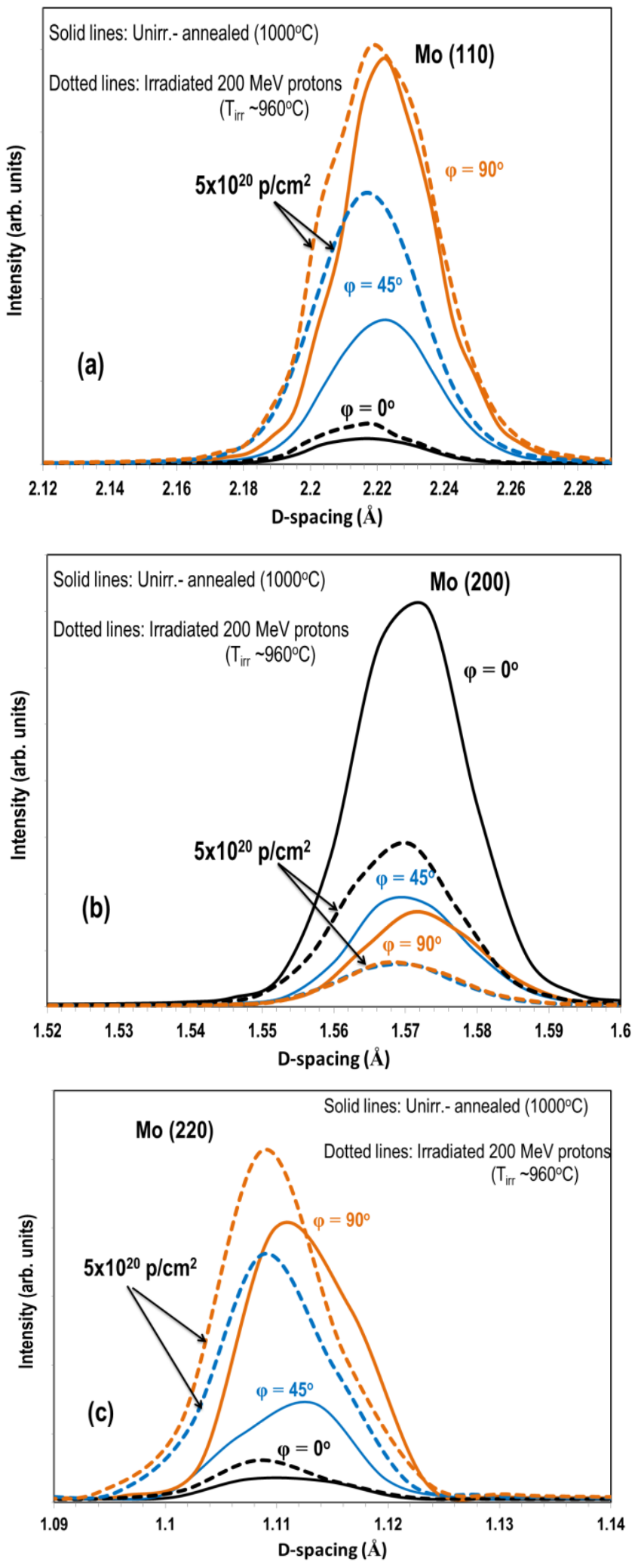

Figure 15: Proton irradiation effects on the microstructure of Mo.
Shown in Figure $16 \mathrm{~b}$ are EDXRD analysis results of the unirradiated CW Mo under high FPB stress. The 3D diffraction map shown represents the evolution from the face of the Mo specimen under highest compression to the opposite face under high tensile stresses. Stemming from the EDXRD technique used to generate the map of Figure 16, the diffraction map is not influenced by surface effects due to the fact the diffraction volume is within the material making the measurements insensitive to any surface phenomena or defects. Detailed analysis of the EDXRD diffraction map of the asreceived, excessively cold worked Mo as well as of the FPB loaded Mo shown in (Figure 16) did not reveal any BCC-to-FCC transformation. EDXRD results shown in Figures $17 \mathrm{a}$ and $17 \mathrm{~b}$ reveal that under high FPB stress straining of the lattice along certain crystal planes occur. Interesting to note is the fact that no straining is visible in the (200) reflection while there is a clear shift between tension and compression for the (220) reflection.

The high-fluency, high temperature CW Mo irradiated with 200 $\mathrm{MeV}$ protons was subjected to similar stress state at the XPD beam line of NSLS II using $67 \mathrm{keV}$ monochromatic X-rays. The corresponding (200) and (220) reflections of Mo under stress is depicted in Figures $17 \mathrm{c}$ and $17 \mathrm{~d}$, respectively. The results using the monochromatic $\mathrm{X}$-rays confirm the results of Figures $17 \mathrm{~b}$ and $17 \mathrm{a}$ obtained using Energy Dispersive diffraction and $200 \mathrm{keV}$ X-rays in that under the imposed stress state the (200) crystal plane does not experience any strain even in following high irradiation dose (i.e., no shift is observed between irradiated and irradiated under high stress (Figure 17c)). The (220), on the other hand is shown in Figure 17d to experience strain, as it is evident from the d-spacing shifting and broadening, similar to the unirradiated state shown in Figure 17b.

\section{Summary and Conclusion}

Cold-worked molybdenum produced by the PLANSEE Group, Austria and characterized by a microstructure consisting of nonuniformly elongated grains of interest as a material for use in the Large Hadron Collider $7 \mathrm{TeV}$ beam halo cleaning system was studied following irradiation to energetic protons [14]. Of interest is the multi-faceted study was the understanding of the thermal stability of the material and the effects proton irradiation on physio-mechanical properties (such as dimensional stability and stress-strain relation) as well as irradiation-induced changes in the microstructure.

Following irradiation exposures of this CW Mo to $200 \mathrm{MeV}$ protons at high temperature and $28 \mathrm{MeV}$ protons at low temperatures, the post-irradiation evaluation consisting of macroscopic assessment and high energy $\mathrm{X}$-ray diffraction revealed the following:

Irradiation under vacuum environment and $\mathrm{T}_{\mathrm{irr}}$ approaching the full re-crystallization temperature of $1100^{\circ} \mathrm{C}$ results in small increases of dimensional stability measures such as thermal expansion coefficient due to the significant thermal annealing that is taking place.

At these high temperature-high measurement conditions, in any case, there are critical changes in the CW Mo material that influence the mechanical conduct and specifically the rigidity and its fragile nature. This is attributed to void-induced swelling, a consequence of the proton irradiation and the high irradiation temperature, which is more prominent in Mo than its TZM alloy, and most importantly on the evolution of defects into dislocation loops and dislocation networks above $600^{\circ} \mathrm{C}$. The mechanical behavior findings in the 
Citation: Simos N, Quaranta E, Charitonidis N, Redaelli S, Bertarelli A, et al. (2017) Proton Irradiation Effects on the Physio-Mechanical Properties and Microstructure of Cold-Worked Molybdenum\$. J Nucl Ene Sci Power Generat Technol 6:4.

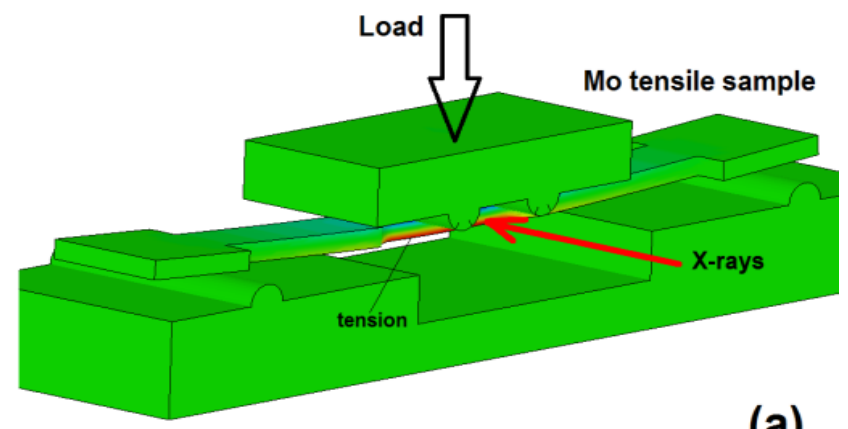

(a)
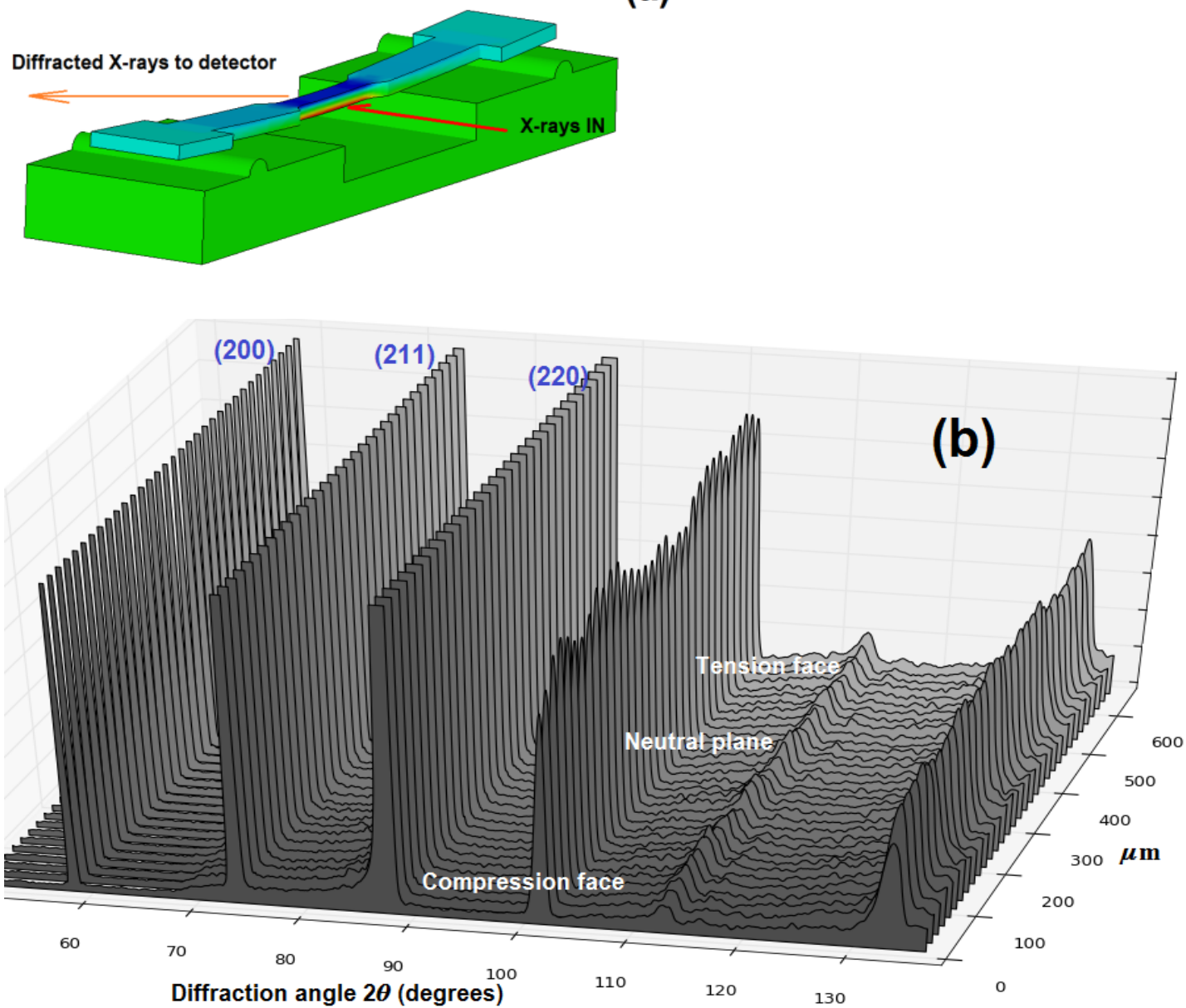

Figure 16: (a) Implemented in situ four-point bending stress with X-ray diffraction, (b) EDXRD analysis of unirradiated CW Mo under in-situ stress using $200 \mathrm{keV}$ "white" X-rays at X17B1 beam line of NSLS.

present study are in agreement with findings by other researchers in irradiation damage studies using fast neutrons and $5 \mathrm{MeV}$ nickel ions over a range of temperatures. It was established in this study that in high dose-high temperature irradiations the $\mathrm{CW}$ Mo fractures at a fraction of the unirradiated tensile strength while showing a ductilelike behavior stemming from the dislocation loop network that has developed.

The high energy X-ray diffraction experiments studying the microstructural evolution revealed the following:

At irradiation temperatures that are far below the re-crystallization of the CW Mo the effect of the irradiation on the microstructure is more pronounced even at lower proton fluency. This was evident following irradiation with $28 \mathrm{MeV}$ protons at low temperature as compared to the $200-\mathrm{MeV}$ proton irradiation at high temperature.

Irradiation at temperatures nearing the full re-crystallization temperature of the material removes the observed microstructure texture induced by the cold working.

X-ray diffraction studies using both polychromatic and monochromatic X-rays with high in-situ stress state from four-point bending did not observe (at least up to the imposed stress level) any BCC-to-FCC transitions in the material. This applies to both unirradiated and irradiated CW Mo. 
Citation: Simos N, Quaranta E, Charitonidis N, Redaelli S, Bertarelli A, et al. (2017) Proton Irradiation Effects on the Physio-Mechanical Properties and Microstructure of Cold-Worked Molybdenum\$. J Nucl Ene Sci Power Generat Technol 6:4.
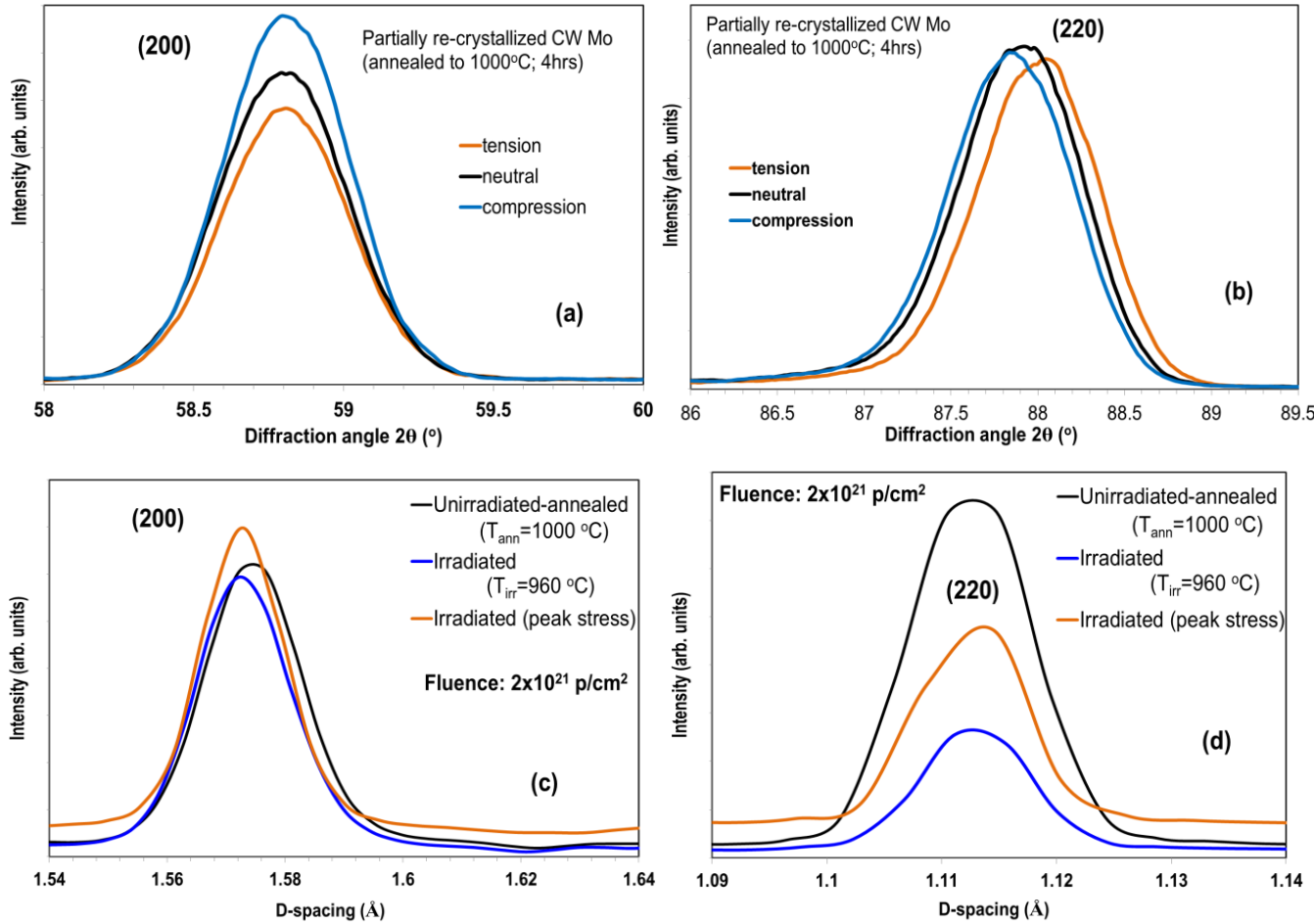

Figure 17: Effect of four-point bending stress on CW Mo lattice deformations. (a) Effects of FPB stress on the (200) reflection of unirradiated-annealed CW Mo deduced from EDXRD and $200 \mathrm{keV}$ X-rays, (b) FPB stress effects on (220) reflection of unirradiated-annealed CW Mo from $200 \mathrm{keV}$ X-rays and EDXRD, (c) FPB on irradiated CW Mo (200) reflection using $67 \mathrm{keV}$ monochromatic X-rays, and (d) FPB on irradiated CW Mo (220) reflection using 67 keV monochromatic X-rays.

\section{References}

1. Zinkle SJ, Ghoniem NM (2000) Operating temperature for fusion reactor structural materials. Fusion Engineering and Design 52: 55-71.

2. Eyre BL, Roberts AC (1965) The nature and annealing behavior of irradiation damage in molybdenum. Flow and Fracture of Metals and Alloys in Nuclear Environments.

3. Zakharova MI, Artemov NA, Bogdanov VV (2001) Effects of neutron irradiation and annealing on the elastic moduli and electrical resistivity of molybdenum and tungsten single crystals. Inorganic Materials 37: 786-789.

4. Kulcinski GL, Brimhall JL (1971) High-temperature heavy ion bombardment of molybdenum, niobium and TZM. Pacific Northwest Laboratories Report CONF-710905-1.

5. Abe K, Masuyama T, Satou M, Hamilton ML (1989) Neutron irradiation damage and void lattice formation in molybdenum alloy TZM. Materials Transactions JIN 34: 1137-1142.

6. Gittus JG (1975) Creep viscoelasticity and creep fracture in solids. Elsevier Science Ltd

7. Brown RD, Cost JR (1982) Mechanical properties of $800-\mathrm{MeV}$ protonirradiated metals. LA-UR-82-672.

8. Wang SJ, Wang H, Du K, Zhang W, Sui ML, et al. (2014) Deformation-induced structural transition in body-centered cubic molybdenum. Nat Commun 5: 1-9

9. Simos N, Zhong Z, Ghose S, Kirk HG, Trung LP, et al. (2016) Radiation damage and thermal shock response of carbon-fiber-reinforced materials to intense high-energy proton beams. Phys Rev Accel Beams 19: 1-20.

10. Matthews RB, Jenkins GM (1975) The high temperature interaction between molybdenum and graphite. J Mater Sci 10: 1976-1990.

11. Simos N, Kirk H, Ludewig H, Thieberger P, Weng WT et al. (2006) Solid target studies for muon colliders and neutrino beams. Nuclear Physics 155 288-290
12. Simos N, Kirk H, Ludewig $H$, Thieberger $P$, Conor JO, et al (2008) Irradiation damage studies of high power accelerator materials. Journal of Nuclear Materials 377: 41-51.

13. N. Simos (2016) Observed anomalies in the refractory metals W, Ta and Mo and the effects of irradiation. Unpublished results.

14. PLANSEE Group, Austria

15. Mariani N (2014) Development of Novel, Advanced Molybdenum-based Composites for High Energy Physics Applications," PhD Thesis, Politecnico di Milano, Milan, Italy

16. Bohlen TT, Cerutti F, Chin MPW, Fasso A, Ferrari A (2014) The FLUKA code: Developments and challenges for high energy and medical applications. Nuclear Data Sheets 120: 211-214.

17. Ferrari A, Sala PR, Fasso A, Ranft J (2005) FLUKA: A multi-particle transport code. CERN. Stanford, CA. USA.

18. LS-DYNA. Version 9.71. Livermore Software Technology Corporation.

19. Hidnert P, Gero WB (1954) Thermal expansion of molybdenum. NIST Scientific Papers of the Bureau of Standards 10: 429-444.

\section{Author Affiliations}

'Brookhaven National Laboratory, Upton, NY, USA

${ }^{2} \mathrm{CERN}, \mathrm{CH}-1211$ Geneva, Switzerland

${ }^{3}$ Stony Brook University, USA

${ }^{4}$ National Centre of Scientific Research, Demokritos, Greece 